in the head, unpleasant abdominal sensation, and an odor. Seizures were localized to various temporal regions, right lateral, right mesial, and independently in both mesial temporal lobes. Two patients with unilateral ictal foci who underwent surgery are seizure free. (Tayah TF, Abou-Khalil B, Gilliam FG et al. Musicogenic seizures can arise from multiple temporal lobe foci: Intracranial EEG analyses of three patients. Epilepsia August 2006;47:1402-1406). (Reprints: Dr MJ Gallagher, Department of Neurology, Vanderbilt University Medical Center, 6140 Medical Research Building III, $46521^{\text {st }}$ Ave, South, Nashville, TN 37232 ).

COMMENT. Musicogenic epilepsy is a heterogeneous syndrome arising from various temporal lobe foci. Resective surgery should be considered for patients with unilateral ictal localization. The first reports of musicogenic epilepsy are usually ascribed to Macdonald Critchley (Brain 1937;60:13-27; cited in Penfield W, Jasper H. Epilepsy and the Functional Anatomy of the Brain, Boston, Little, Brown; 1954;p39), although earlier references, notably one involving Berlioz, are mentioned by Lennox WG. (In Epilepsy and Related Disorders, Boston, Little, Brown; 1960;pp361-365). Adults appear to be affected more frequently than children.

\title{
MITOCHONDRIAL PROFILES AND THE ANTICONVULSANT EFFECT OF THE KETOGENIC DIET
}

A study of the anticonvulsant effect of the ketogenic diet (KD) in adolescent rats, at Emory University and other centers, found that the hippocampus responds by inducing mitochondrial biogenesis, enhancing metabolic gene expression, and increasing energy reserves. The density of mitochondrial profiles in the dentate gyrus was increased by $46 \%$. An energy preservation hypothesis leading to alternative energy stores is proposed for the diet, especially important for the survival and function of GABAergic interneurons under stressful conditions. (Bough KJ, Wetherington J, Hassel B et al. Mitochondrial biogenesis in the anticonvulsant mechanism of the ketogenic diet. Ann Neurol August 2006;60:223-235). (Respond: Dr Bough, Food and Drug Administration, Center for Drug Evaluation and Research, MPN 1, Room 1345, 7520 Standish Place, Rockville, MD 20855).

COMMENT. These authors propose that chronic ketosis activates a genetic program that leads to mitochondrial biogenesis in the hippocampus, resulting in enhanced energy stores. Sustained ATP levels during stress allow membrane stabilization and elevation of the seizure threshold. Alternative mechanisms of action of the ketogenic diet previously proposed have included the anesthetic effects of ketone bodies, the associated acidosis, and changes in electrolytes. In clinical balance studies performed at the Mayo Clinic, where the diet was first introduced (Wilder RM. Mayo Clin Bull 1921;2:307), an anticonvulsant effect was unrelated to diuresis, independent of acidosis and ketosis, and was correlated with an increased urinary excretion and negative balance of sodium and potassium (Millichap JG, Jones JD. Epilepsia 1964;5:239-255). In animal studies, an anticonvulsant effect of a high fat, low carbohydrate diet was demonstrated in mice with a seizure threshold first lowered by water intoxication and hypoelectrolytemia; seizure susceptibility was not modified by a similar diet in normal animals (Millichap JG et al. Amer J Dis Child 1962;104:506; idem/ibidem 1964;107:593-604). 